OPEN ACCESS

Edited by:

Alejandro Berlin

Princess Margaret Cancer Centre,

Canada

Reviewed by:

Neil B. Desai,

University of Texas Southwestern Medical Center, United States

Rachel Glicksman,

University of Toronto, Canada

*Correspondence:

Thomas Zilli

Thomas.Zilli@hcuge.ch

Specialty section: This article was submitted to

Genitourinary Oncology,

a section of the journal

Frontiers in Oncology

Received: 15 July 2021 Accepted: 09 August 2021 Published: 31 August 2021

Citation:

le Guevelou J, Achard V, Mainta I,

Zaidi H, Garibotto V, Latorzeff I, Sargos P, Ménard C and Zilli T (2021)

PET/CT-Based Salvage Radiotherapy for Recurrent Prostate Cancer After Radical Prostatectomy: Impact on Treatment Management and Future Directions.

Front. Oncol. 11:742093. doi: 10.3389/fonc. 2021.742093

\section{PET/CT-Based Salvage Radiotherapy for Recurrent Prostate Cancer After Radical Prostatectomy: Impact on Treatment Management and Future Directions}

\author{
Jennifer le Guevelou ${ }^{1,2}$, Vérane Achard ${ }^{1,3}$, Ismini Mainta ${ }^{4}$, Habib Zaidi ${ }^{3,4,5,6,7}$, \\ Valentina Garibotto ${ }^{3,4,5}$, Igor Latorzeff ${ }^{8}$, Paul Sargos $^{9}{ }^{\text {, }}$ Cynthia Ménard $^{10}$ \\ and Thomas Zilli ${ }^{1,3 *}$ \\ 1 Division of Radiation Oncology, Geneva University Hospital, Geneva, Switzerland, ${ }^{2}$ Division of Radiation Oncology, Centre \\ François Baclesse, Caen, France, ${ }^{3}$ Faculty of Medicine, Geneva University, Geneva, Switzerland, ${ }^{4}$ Division of Nuclear \\ Medicine and Molecular Imaging, Diagnostic Department, Geneva University Hospital, Geneva, Switzerland, 5 Geneva \\ Neuroscience Center, Geneva University, Geneva, Switzerland, ${ }^{6}$ Department of Nuclear Medicine and Molecular Imaging, \\ University of Groningen, University Medical Center Groningen, Groningen, Netherlands, ${ }^{7}$ Department of Nuclear Medicine, \\ University of Southern Denmark, Odense, Denmark, ${ }^{8}$ Department of Radiation Oncology, Groupe Oncorad-Garonne, \\ Clinique Pasteur, Toulouse, France, ${ }^{9}$ Department of Radiation Oncology, Institut Bergonié, Bordeaux, France, ${ }^{10}$ Department \\ of Radiation Oncology, Centre Hospitalier de l'Université de Montréal (CHUM), Montréal, QC, Canada
}

Biochemical recurrence is a clinical situation experienced by 20 to $40 \%$ of prostate cancer patients treated with radical prostatectomy $(\mathrm{RP})$. Prostate bed $(\mathrm{PB})$ radiation therapy $(\mathrm{RT})$ remains the mainstay salvage treatment, although it remains non-curative for up to $30 \%$ of patients developing further recurrence. Positron emission tomography with computed tomography (PET/CT) using prostate cancer-targeting radiotracers has emerged in the last decade as a new-generation imaging technique characterized by a better restaging accuracy compared to conventional imaging. By adapting targeting of recurrence sites and modulating treatment management, implementation in clinical practice of restaging PET/CT is challenging the established therapeutic standards born from randomized controlled trials. This article reviews the potential impact of restaging PET/CT on changes in the management of recurrent prostate cancer after RP. Based on PET/CT findings, it addresses potential adaptation of RT target volumes and doses, as well as use of androgen-deprivation therapy (ADT). However, the impact of such management changes on the oncological outcomes of PET/CT-based salvage RT strategies is as yet unknown.

Keywords: prostate cancer, relapse, radiotherapy, PET/CT, PSMA, choline, fluciclovine, oligometastatic

\section{INTRODUCTION}

Between 20 and $40 \%$ of patients treated with radical prostatectomy (RP) will develop biochemical recurrence (BCR) (1-3), defined as a confirmed rising prostate specific antigen (PSA) during the postoperative follow-up (4). The risk is greater among patients with high-risk features, such as extraprostatic extension, seminal vesicles invasion, or positive surgical margins (5). 
Four randomized trials have shown a twofold reduction in BCR with adjuvant radiotherapy (RT) compared with observation for patients with high-risk features (6-9), resulting in a potential improvement in both metastasis-free survival and overall survival (10). Still, adjuvant RT has been withdrawn in favor of early salvage radiotherapy (SRT), associated with the same oncological benefit for the majority of relapsing patients without high-risk features (11-14), when performed at low PSA values (15). Furthermore, this shift in practice avoids the use of immediate adjuvant RT, and the associated toxicity, in approximately $40 \%$ of patients (12).

The role of restaging imaging is not clearly defined in the salvage setting, and current guidelines recommend irradiation of the prostate bed $(\mathrm{PB})$ with or without the whole pelvis using standardized anatomic-based contouring atlases (16-18). Based on current evidence, SRT remains, however, non-curative for some patients, raising concerns about the potential role of restaging at $\mathrm{BCR}$ and the appropriateness of irradiation volumes and/or radiation doses used in this setting.

In the last decade, positron emission tomography with computed tomography (PET/CT) using new radiotracers has emerged in clinical practice as a new imaging modality, proving both higher sensitivity and specificity than conventional imaging in detecting recurrence after RP $(19,20)$. By providing more accurate staging, PET can potentially lead to significant adjustments in treatment management. Together with advances in RT techniques, PET imaging may therefore offer novel perspectives for treatment optimization, such as metastasis-directed therapy (MDT), thereby challenging the established therapeutic standards.

This narrative review aims to assess the influence of PET/CT on treatment changes for salvage postoperative radiation treatment in prostate cancer patients with BCR after RP. Potential modification of target volumes, RT doses, and use of androgen-deprivation therapy (ADT) for SRT treatments based on PET/CT findings are considered and discussed.

\section{MODERN IMAGING MODALITIES IN PROSTATE CANCER: PET/CT}

The benefit to performing local treatment such as RT is critically dependent upon imaging methods and its accuracy to assess disease at local, nodal, and metastatic level (Figure 1). Traditionally, computed tomography (CT) and bone scintigraphy have been used for both staging and follow-up of patients with prostate cancer, yet they often lead to understaging. Indeed, CT was shown to have a $32 \%$ sensitivity only in detecting nodal metastases in a meta-analysis led by Hövels et al. (19), with both sensitivity and specificity dropping precipitously at low PSA levels, when indication for SRT is usually undertaken. Bone scintigraphy remains the standard for the detection of bone lesions, but pooled results from a meta-analysis revealed a sensitivity and specificity of 59 and $75 \%$, respectively (20).

Radiolabeled choline is one of the most extensively studied tracers in the restaging of prostate cancer in BCR (21). It is a substrate for choline kinase, upregulated in rapidly duplicating cells to meet the increased demands for membrane phospholipid synthesis, a biomarker associated with cell proliferation (22). ${ }^{18}$ Fcholine PET/CT was found to have a diagnostic accuracy of $84 \%$, with a sensitivity of $79 \%$ and a specificity of $97 \%$ in bone evaluation (23), while its sensitivity ranges from 33 to $100 \%$ for nodal disease assessment, with a specificity of $97 \%$ (24). Most of its limitations come in the restaging performance of patients with a PSA level $<2 \mathrm{ng} / \mathrm{ml}$ and with a doubling time $>6$ months (25). Still, European Association of Urology (EAU) guidelines recommend to perform choline PET/CT at BCR if PSA value is $>1 \mathrm{ng} / \mathrm{ml}$ (4).

${ }^{18}$ F-Fluciclovine PET/CT is also indicated at BCR, after primary treatment with curative intent $(26,27)$. It has the ability to detect amino acid transport, which is upregulated in numerous types of cancer cells (28). Fluciclovine PET/CT was found to be both more sensitive (45 vs 21\%) and more specific (29 vs $14 \%$ at PSA values $<1 \mathrm{ng} / \mathrm{ml}$ ) than choline PET/CT (29), and thus received approval by the Food and Drug Administration (FDA) in the recurrent setting. In the phase III FALCON trial, the detection rate of Fluciclovine was $56 \%$ at a median PSA level at restaging of $0.79 \mathrm{ng} / \mathrm{ml} \mathrm{(30).}$

PET/CT using Prostate Specific Membrane Antigen (PSMA) radiotracer, either radiolabeled with ${ }^{68} \mathrm{Ga}$ or ${ }^{18} \mathrm{~F}$, detects cellular expression of PSMA and is being increasingly used in the staging of prostate cancer patients $(31,32)$. In a population of high-risk localized prostate cancer, PSMA PET/CT was shown to have a $27 \%$ greater accuracy than conventional imaging (92 vs 65\%, $\mathrm{p}<0.0001$ ), with a sensitivity of $85 \%$ and a $98 \%$ specificity (33). In the recurrent setting, PSMA PET/CT showed excellent detection rates even at very low PSA values ( $42 \%$ for PSA levels $\leq 0.2 \mathrm{ng}$ / $\mathrm{ml}$ ) (34). Still, cautious evaluation is required in case of solitary PSMA-avid lesions, especially on the bones, as they may be falsepositive findings (Figure 2) (35). Currently, EAU guidelines recommend performing PSMA PET/CT at BCR if the PSA level is $>0.2 \mathrm{ng} / \mathrm{ml}$ and if the results will influence subsequent treatment decisions (4). Other jurisdictions have neither approved nor funded PSMA PET/CT given an absence of evidence demonstrating impact on improved patient outcomes.

\section{LOCAL RELAPSE}

Radiation therapy to the $\mathrm{PB}$ is the standard salvage therapy in men who have developed BCR after RP (36). Areas deemed at risk of local recurrence include the vesicourethral anastomosis, the retrovesical region, and the bladder neck (37). Still, despite the performance of SRT, up to $8 \%$ of the patients will develop local recurrence (38), highlighting the importance of both an adequate radiation dose and an accurate clinical target volume (CTV) definition.

To date, several guidelines have been published to standardize postoperative target volume: the Radiation Therapy Oncology Group (RTOG) (39), the European Organisation for Research and Treatment of Cancer (EORTC) (17), the Faculty of Radiation Oncology Genito-Urinary Group (FROGG) (40), the Genito Urinary Radiation Oncologists of Canada (GUROC) (41), and the 

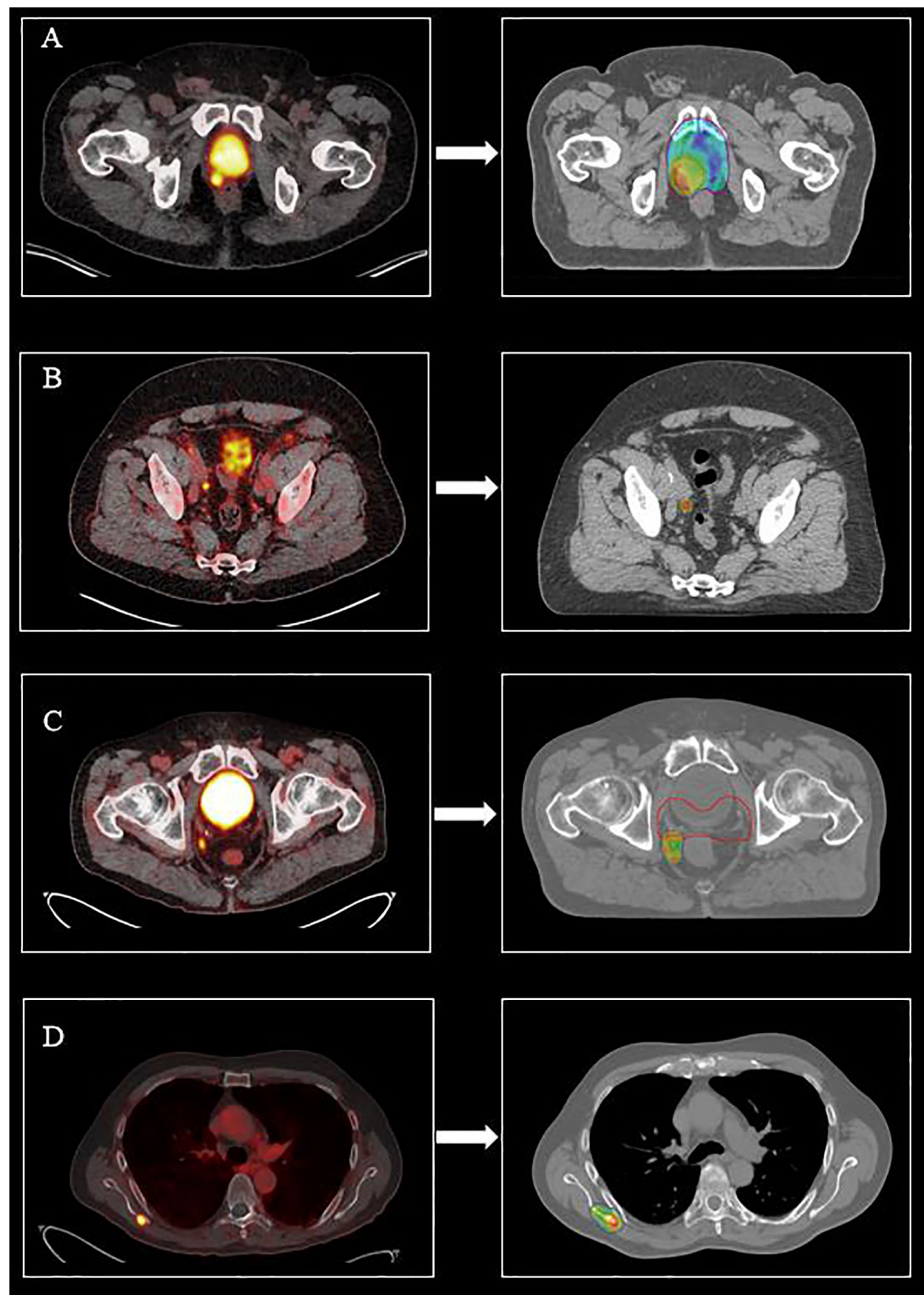

FIGURE $1 \mid{ }^{68} \mathrm{Ga}$-PSMA PET/CT restaging findings and the corresponding salvage radiotherapy treatments (color wash isodose line $95 \%$ ) in patients with biochemical recurrent prostate cancer after radical prostatectomy. (A) ${ }^{68} \mathrm{Ga}$-PSMA PET/CT revealing a prostate bed recurrence located close to the bladder neck (left). Prostate bed radiotherapy (64 Gy/32 fx) planned with a simultaneous integrated boost (70.4 Gy/32 fx) (right) to the PET/CT positive lesion. (B) ${ }^{68} \mathrm{Ga}$ PSMA PET/CT revealing a millimetric solitary right external iliac node (left). Salvage stereotactic body radiation therapy planned on the PSMA avid node (30 Gy/3 fx) (right). (C) ${ }^{68}$ Ga PSMA PET/CT revealing a perirectal oligorecurrent nodal relapse after radical prostatectomy and salvage prostate bed radiotherapy (left). Stereotactic body radiation therapy planned on the PSMA avid node (35 Gy/5 fx). Prostate bed PTV is shown in red (right). (D) ${ }^{68} \mathrm{Ga}$ PSMA PET/CT revealing an oligometastatic bone metastasis located at the right scapula (left). Stereotactic body radiation therapy planned to the PET/CT positive bone lesion (30 Gy/3 fx). 


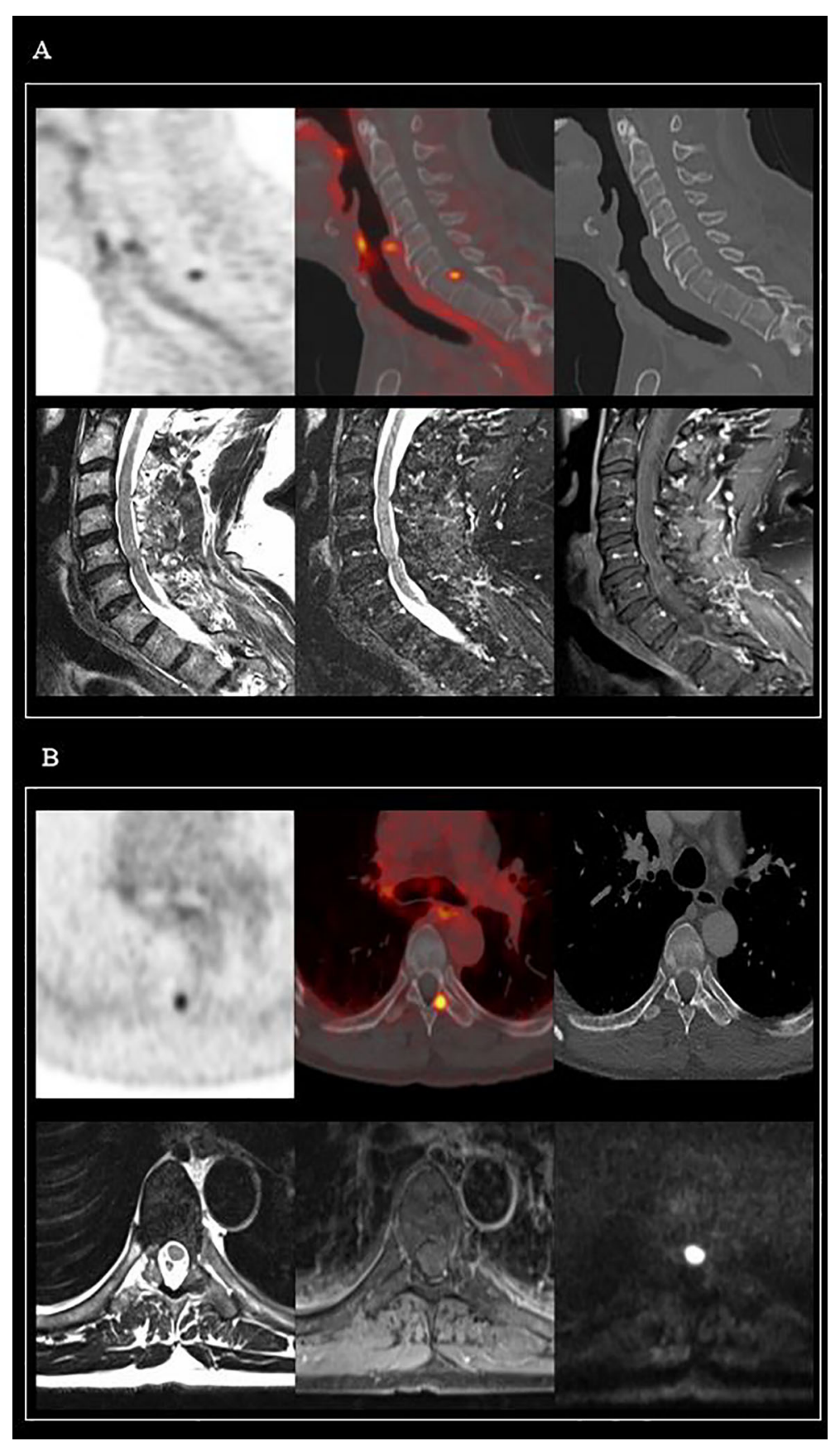

FIGURE 2 | Two cases of PSMA-avid bone uptakes, with no evidence of metastatic lesions on MRI imaging. (A) ${ }^{68}$ Ga-PSMA PET/CT: Millimetric and PSMA-avid bone lesion on the posterior part of the vertebral body of C7. MRI (from left to right): T2 TSE, T2, and T1 TSE FS Gadolinium MRI sequences, all in favor of a benign bone lesion. (B) ${ }^{68}$ Ga-PSMA PET/CT: Avid bone lesion at the base of the left transverse process of the D7 vertebra. MRI (from left to right): T2 TSE, T1 TSE FS Gadolinium, and b800 diffusion MRI sequences, all in favor of a benign bone lesion.

Francophone Group of Urological Radiation Therapy (GFRU) (16). These standardized volumes do not, however, cover all potential sites of recurrence. In a study assessing the patterns of local relapse in patients with BCR after RP, the anastomosis was the most common site of recurrence $(52.8 \%)$ identified by ${ }^{18} \mathrm{~F}$-Choline $\mathrm{PET} / \mathrm{CT}$, followed by the retrovesical region $(31.7 \%)$ and the bladder neck (7\%) (42). Eighty-four percent and 83\% of local relapses were entirely included in CTV, defined according to RTOG and FROGG guidelines, respectively. This rate was significantly lower using the EORTC guidelines $(68 \%$, $\mathrm{p}=0.006$ ), due to a lack of coverage of the bladder neck and the retrovesical region. Still, $60 \%$ of relapses occurring in the 
posterior region of the anastomosis were not covered by any of the CTVs. Extending the target volumes in a standardized manner would necessarily result in an increased dose to organs at risk (OAR), which may ultimately increase the risk of late toxicity, particularly in the urinary tract. On the other hand, personalization of target volumes and radiation doses by implementing restaging PET/CT can potentially improve the therapeutic ratio of recurrent patients who are candidates for SRT.

Management of local macroscopic recurrence after RP is characterized by a high variability of treatment paradigms (43). Use of focal boost with or without whole pelvis irradiation (44), addition of concomitant short-term or long-term ADT $(45,46)$, or delivery of a focal SBRT to the macroscopic relapse (47) have been hypothesized as possible alternatives to SRT to the PB only.

A focal boost on the PET-positive local recurrence represents one the mostly studied potential contributions of functional imaging. In a study including 60 patients, D’Angelillo et al. reported a focal boost of up to 80 Gy to a biological target volume (BTV) defined by ${ }^{18} \mathrm{~F}$-Choline PET/CT. The 3-year biochemical progression-free survival rate was $72.5 \%$, with only three patients experiencing grade 3 acute gastrointestinal toxicity, and no grade 3 late toxicity (48). Still, detection of local recurrence remains challenging as ${ }^{18} \mathrm{~F}$-Choline PET/CT suffers from a low spatial resolution with inconsistent sensitivity in this setting, ranging from $64 \%$ to $100 \%$ (25). In addition, the low sensitivity of choline PET at PSA values $<2 \mathrm{ng} / \mathrm{ml}$ and in case of doubling time $>6$ months makes this diagnostic modality poorly suitable for patients eligible for early SRT. At low PSA values, PSMA PET/ CT appears to be the best diagnostic option, with detection rates of about $50 \%$ at PSA levels of less than $0.5 \mathrm{ng} / \mathrm{ml}(49,50)$. Calais et al. reported the diagnostic performance of PSMA PET/CT and Fluciclovine PET/CT in a population of patients with BCR after RP (51). Detection rates were significantly lower with ${ }^{18} \mathrm{~F}$ Fluciclovine PET/CT than with PSMA PET/CT (26 vs 56\%, $\mathrm{p}=0.0026$ ). However, on a local level, the assessment by PSMA PET, especially with ${ }^{68} \mathrm{Ga}$, may be limited due to urinary excretion of the tracer. This was emphasized in a study conducted by Pernthaler et al. (52) in a population of patients with BCR, where a higher rate of prostatic recurrence was found with Fluciclovine PET than PSMA PET (37.9 vs 27.6\%, p=0.03). In the EMPIRE-1 trial (53), prostate cancer patients with BCR were randomly assigned in two arms: the first received SRT based on conventional imaging, the second underwent Fluciclovine $\mathrm{PET} / \mathrm{CT}$, and treatment was planned according to those findings. In case of pelvic nodal uptake, patients received $\mathrm{PB}$ and pelvic RT, with nodal boost up to 54-56 Gy. In case of PB-only uptake, patients received PB RT, with a boost up to 76 Gy on the local recurrence. When no uptake was found, patients were treated on the PB only. The 3-year failure-free survival was superior in patients treated with Fluciclovine PET/CT-guided SRT compared to patients treated using conventional imaging only (75.5 vs 63\%). This difference widened at the 4-year evaluation (75.5 vs $51.2 \%, \mathrm{p}=0.001$ ) (54), which can be attributable to both a stage-migration phenomenon and a reduction of the in-field relapses related to the SRT dose escalation. Regardless of some inherent limitations [low proportion of patients receiving whole pelvis RT (WPRT), $25 \%$ of patients with a PSA level $>1 \mathrm{ng} / \mathrm{ml}$ at salvage, lack of intent-to-treat analysis], this study can be considered hypothesis generating with respect to a possible improvement in outcomes with PET-guided SRT.

In an attempt to further reduce toxicity and improve outcome, focal treatments directed to the local PB relapse using modern SBRT techniques have been proposed as the last frontier of SRT (47), with promising preliminary results requiring, however, further prospective validation.

Isolated macroscopic local recurrence after RP remains a rare situation, representing $12 \%$ of BCR cases in a study by Calais et al. using restaging PSMA PET/CT on a population with a PSA value $<1 \mathrm{ng} / \mathrm{ml}$ (55). Whether or not to treat pelvic lymph nodes in this setting remains an open question. In an analysis of recurrence patterns after PB RT, Douglas et al. reported up to a $39 \%$ of isolated pelvic nodal failure after SRT to the PB (56). To date, in this population of relapsing patients after RP, the results of the NRG Oncology/RTOG 0534 SPPORT trial demonstrated the superiority of WPRT + PB RT over PB RT alone, both combined with a short course of ADT (44). Exploratory subgroup analyses of this trial suggested that the benefit for nodal irradiation was more pronounced for men with a PSA $>0.34 \mathrm{ng} / \mathrm{ml}$ at the time of salvage treatment. However, restaging modalities used in this study were not based on modern imaging. Irradiating or not the whole pelvis in node-negative PSMA patients remains therefore an open question, requiring prospective evaluation. Noteworthy, even with PSMA PET/CT, the detection of lymph node metastases is moderate (33-91\%), due to the inherent limitations in spatial resolution to detect small $(<3 \mathrm{~mm})$ nodal metastases (57). Besides, men at high-risk of micro-metastatic nodal involvement are probably the most likely to benefit from WPRT (58).

\section{NODAL RELAPSE}

Lymph nodes are commonly identified as a site of failure in prostate cancer, particularly in the post-RP setting, followed by distant bone metastases (59). Although nodal relapses after RP follow common patterns of disease spread in the majority of the cases, a relevant percentage of patients exhibit nevertheless an aberrant nodal spread. In a study of Meijer et al. using magnetic resonance lymphography (60), 79\% of the patients presented an aberrant lymph node spread, most of them being located in the perirectal region and in the para-aortic region. Using PSMA PET/CT in a population of patients with PSA $<1 \mathrm{ng} / \mathrm{ml}$ after RP, Calais et al. also supported the finding that perirectal lymph nodes are the most common site of nodal recurrence outside the pelvic CTV (55). Implementing PET/CT studies data on patterns of nodal relapse, recent guidelines as the NRG Oncology Updated International Consensus atlas recommend cranial extension of CTV volumes to include the common iliac nodes (18). Inclusion of peri-rectal nodes in the CTV volume remains a source of discussion, especially for T4 tumors (61).

PET/CT imaging can be used to provide guidance for the realization of a boost, in case of intrapelvic nodal recurrence. Fodor et al. reported the 3-year toxicity and outcomes of a 
choline PET/CT-guided RT in patients with a nodal relapse. Pelvic and/or lombo-aortic irradiation was performed at $51.8 \mathrm{~Gy} / 28$ fractions, with simultaneous integrated boost (SIB) technique to a median dose of $65.5 \mathrm{~Gy}$ on the pathological uptake sites. Ninety-one percent of the patients had a PSA reduction 3 months after RT, with a 3-year clinical relapse free survival of $61.8 \%$ (62). The single-arm phase II Oligopelvis-GETUG P07 trial also explored the role of concomitant salvage pelvic irradiation with moderate hypofractionation (54 Gy/30 fractions to the pelvis, 66 Gy/30 fractions the lymph nodes) in combination with 6 months of ADT. A persistent complete biochemical response was found in 73.1 and $45.9 \%$ of the patients at 2 and 3 years, respectively, with a 2-year progression-free survival (PFS) of $77.6 \%(63,64)$.

MDT strategies using stereotactic body radiotherapy (SBRT) have been widely used as an alternative to elective nodal irradiation. Many teams reported on outcomes after MDT alone, enrolling heterogeneous populations with both nodal and bone metachronous metastases, and both ADT and non-ADT treated patients. Local control and ADT-free survival were the most common endpoints. The STOMP trial (65) randomized patients with one to three metastases (55\% of the patients with nodal disease, $45 \%$ with bone metastases) detected by Choline PET/CT studies to MDT (SBRT or salvage lymph node dissection, sLND) or observation. Median ADT-free survival was in favor of performing MDT (21 months vs 13 months), with a greater benefit among patients with PSA doubling time $<3$ months. Similarly, the ORIOLE study confirmed the benefit of MDT in terms of biochemical control in a population of recurrent patients diagnosed with oligometastatic disease by PSMA PET/CT (66). The proportion of men with disease progression at 6 months was 19\% among patients treated with MDT compared to $61 \%$ in the observation arm $(\mathrm{p}=0.005)$. Of note, total consolidation of PSMA -avid lesions decreased significantly the risk of new lesions at 6 months (16 vs 63\%). Although results of MDT studies are encouraging, whether or not to perform WPRT in combination with MDT remains an unresolved issue with large variability in the treatment volumes proposed in patients with oligorecurrent nodal disease (67). Initial series with choline PET/CT seemed to discourage the planning process of MDT on only positive spots (68). Even when PSMA PET/CT is used, surgical series have showed that bilateral and extended treatment of nodal disease is more likely to provide complete biochemical response than targeted node dissection. In a study by Siriwardana et al. (69), 90\% of patients achieved a biological complete response after bilateral sLND compared with 33.3 and $21.4 \%$ in those undergoing unilateral and targeted node dissection, respectively. Also, Ploussard et al. reported after sLND heterogeneous results in terms of biochemical progression-free survival, ranging from 23 to $64 \%$ at 2 years (70). In analogy, subsequent relapses after SBRT for oligometastatic nodal recurrences are again nodal and oligometastatic (71). Despite better results compared with choline PET/CT, the sensitivity of PSMA PET/CT seems insufficient to warrant the performance of focal nodal MDT, in order to obtain biological complete response. Further insights into the benefit and toxicity of elective nodal irradiation will be provided by the results of the PEACE V STORM prospective randomized phase II trial, assessing the potential of combined WPRT and MDT as compared to MDT alone on metastasis-free survival of patients with nodal oligorecurrent prostate cancer $(72,73)$.

\section{EXTRAPELVIC OLIGOMETASTATIC RELAPSE}

Implementation of PET restaging in the therapeutic workflow of prostate cancer patients relapsing after RP can lead to a modified TNM staging in up to $45.2 \%$ of the patients in comparison with conventional imaging modalities (74). In most of the cases, PSMA PET/CT upstages a subset of patients to an M1 status who otherwise would be staged M0 by conventional imaging (75). By modifying the treatment management in about half of the situations $(27,30$, 32, 34), and individualizing RT volumes (Table 1), PET/CT imaging may play a role for a better selection of patients eligible for local salvage therapies. Still, caution is needed when modifying treatment strategy (particularly from a curative to a palliative intent), as PET/ CT restaging may be questioned on its strong evidence of improved therapeutic outcomes (76). Particularly in situations where the discovery of a metastatic lesion shifts the treatment towards a palliative intent, a pathological confirmation may be warranted before making any therapeutic decision.

An increase in the frequency of patients diagnosed with oligometastatic prostate cancer is expected if PET/CT is incorporated into routine care $(77,78)$. Evidence grows for the treatment of these lesions with MDT, such as SBRT or surgery, in association with systemic therapies or not $(79,80)$. Promising results of SABR-COMET showed an improved overall survival (OS) in patients randomized to receive SBRT in addition of standard of care (SOC), compared to SOC alone (41 vs 28 months, $\mathrm{p}=0.09$ ). In prostate cancer, the argument of aggressive local treatments is supported by the recent finding that indolent metastatic lesions have the potential to transform and become aggressive foci of accelerated metastases $(81,82)$. A recent systematic review summarized the use of SBRT for PET/CT proven oligometastatic prostate cancer (83). This study demonstrated excellent local outcomes, with no local recurrences when RT dose exceeded a biologically effective dose (BED) of $>108 \mathrm{~Gy}$ $(\alpha / \beta=3 \mathrm{~Gy})$. Two-year PFS was reported in seven studies, and ranged from 30 to 64 months. For patients that did not receive concomitant ADT, median ADT-free survival ranged from 12.3 months to 39.7 months.

However, despite being able to postpone systemic therapies and probably improve survival outcomes, MDT strategies remain investigational in this setting. Trials comparing MDT with or without systemic therapies with SOC treatments (84-86) are crucially needed to confirm the benefits on both PFS and OS of this emerging therapeutic strategy.

\section{BIOCHEMICAL RELAPSE AND NEGATIVE PET/CT IMAGING}

At PSA levels defining BCR after RP, detection rates of macroscopic disease are low even with PSMA PET/CT, with a $45 \%$ detection rate 
TABLE 1 | Prospective trials evaluating the management change rate after restaging PET/CT in prostate cancer patients with biochemical recurrence after radical prostatectomy.

\begin{tabular}{|c|c|c|c|c|}
\hline Trial & $\mathbf{N}$ & Study design & Primary endpoint & Results \\
\hline $\begin{array}{l}\text { Andriole et al. (27) } \\
\text { LOCATE - } \\
\text { NCT02680041 }\end{array}$ & 114 & $\begin{array}{l}\text { Prospective trial: } \\
{ }^{18} \text { F-Fluciclovine }\end{array}$ & Management change post scan & $\begin{array}{l}\text { - Management change: } 48 \% \\
\text { (32\% omission SRT; } 16 \% \text { change } \\
\text { in SRT volumes) }\end{array}$ \\
\hline $\begin{array}{l}\text { Scarsbrook et al. (30) } \\
\text { FALCON - } \\
\text { NCT02578940 }\end{array}$ & $\begin{array}{c}104 \\
(63 \% \mathrm{RP})\end{array}$ & $\begin{array}{l}\text { Prospective trial: } \\
{ }^{18} \text { F-Fluciclovine }\end{array}$ & Management change post scan & $\begin{array}{l}\text { - Management change: } 64 \% \\
\text { - PSA response rate: } 72 \% \text { without } \\
\text { PET/CT guidance vs } 88 \% \text { with } \\
\text { PET/CT guidance }\end{array}$ \\
\hline $\begin{array}{l}\text { Morris et al. (32) } \\
\text { CONDOR - } \\
\text { NCT03739684 }\end{array}$ & 208 & $\begin{array}{l}\text { Prospective trial: } \\
{ }^{18} \text { F-DCFPyL (PyL) } \\
\text { PSMA }\end{array}$ & $\begin{array}{l}\text { Correct localization rate (CLR) vs composite standard } \\
\text { of truth }\end{array}$ & $\begin{array}{l}\text { - CLR: } 84.8 \% \text { to } 87.0 \% \text { (positive } \\
\text { trial) } \\
\text { - Management change: } 63.9 \%\end{array}$ \\
\hline NCT02940262 & $\begin{array}{l}\text { 1200, active not } \\
\text { recruiting }\end{array}$ & $\begin{array}{l}\text { Prospective trial: } \\
{ }^{68} \text { Ga-PSMA }\end{array}$ & $\begin{array}{l}\text { Sensitivity of }{ }^{68} \mathrm{Ga}-\mathrm{PSM} \text { for detection of tumor } \\
\text { location }\end{array}$ & $\begin{array}{l}\text { - Management change: } 53 \% \\
\text { (ancillary study of } 161 \text { recurrent } \\
\text { patients) (34) }\end{array}$ \\
\hline
\end{tabular}

at PSA levels ranging from 0.2 to $0.49 \mathrm{ng} / \mathrm{ml}$ (50). Considering actual evidence converging on the inverse correlation between the PSA level at SRT and long-term disease control of SRT, guidelines recommend use of early SRT to the PB at PSA level $<0.5 \mathrm{ng} / \mathrm{ml}$, even in absence of specific target (4). Noteworthy, very early SRT (PSA 0.01 to $0.2 \mathrm{ng} / \mathrm{ml}$ ) was associated with a twofold decrease in biochemical failure, use of salvage ADT, and distant metastases compared to early SRT (PSA between 0.2 to $0.5 \mathrm{ng} / \mathrm{ml}$ ) (87). Similarly, Fossati et al. also concluded that SRT should be given at the earliest sign of PSA rise, and even more so in case of adverse pathological findings (pT3b/pT4, Gleason score $>8$, positive surgical margins) (88). Also, the kinetics of PSA rise has an impact on OS, with a significant difference between patients with a PSA doubling time of less than 10 months (36). Could the addition of PET/CT to the design of these studies have affected outcomes? At the very least, it could have enabled the distinction between patients with and without macroscopic disease, resulting in a better homogeneity of the population. It is possible that the association between PSA level at SRT and outcome may be a bias related to the presence of macroscopic disease, and thus undertreatment of a certain proportion of this population. Still, it seems intuitive that providing SRT at a time when the disease is microscopic (and therefore undetectable on PET/CT) yields better outcomes in comparison with macroscopic disease. Indeed, in the study led by Emmett et al., patients who benefited the most from PB SRT were those with a negative PET/CT, with a 3-year freedom from progression evaluated at $82.5 \%(89,90)$. The impact of PET/CT in SRT planning on long-term clinical outcomes is currently assessed by ongoing phase III trials (Table 2). While awaiting the results of these studies, a negative restaging PET/CT at BCR should not delay and alter the decision to perform SRT (4).

\section{DISCUSSION}

PET/CT is gradually being incorporated into international guidelines and is increasingly performed at various stages of the disease. ${ }^{18}$ F-Fluciclovine, ${ }^{68}$ Ga-PSMA, and ${ }^{18}$ F-DCFPyL PET/CT are currently approved by the Food and Drug Administration (FDA) for men with suspected prostate cancer recurrence, but worldwide approval and funding awaits evidence of improved patient outcomes.

PET/CT has proven its accuracy in restaging patients either in the local, nodal, or metastatic setting. Several studies have already proven that the implementation of PET/CT resulted in a significant management change rate in the postoperative setting, ranging from $35 \%$ (54) to $64 \%$ (30) (Tables 1, 2). Still, the question whether improved staging and resultant change in management can improve clinical outcomes remains at the moment unanswered and requires confirmation in prospective trials (Table 2) (54, 89-91). For example, while PET/CT restaging leads us to the definition of an entirely new population of metastatic patients, their prognosis differs dramatically from the old population of metastatic patients. This effect, known as the "Will Rogers Phenomenon" (76), makes us reconsider the treatments established as a gold standard in recent years. A summary of the outstanding issues in treatment management generated by $\mathrm{PET/CT}$ restaging in patients with BCR after RP is provided in Figure 3.

Even the most accurate imaging modalities only allow us to determine the status of the disease at a given moment, without allowing us to foresee its long-term outcome. Genomic biomarkers are crucially needed in order to discriminate between an indolent or aggressive disease and provide data to guide treatment decision. Some commercially available tools have already provided new insights in identifying men with high risk of adverse outcomes (92). Cooperberg et al. demonstrated the ability of a panel of genes associated with cell cycle progression in predicting BCR after RP (93). The same panel of genes, in association with housekeeping genes, has been commercialized in the Prolaris test, which has proven its relevance in the decision of an adjuvant treatment in case of adverse pathological findings after RP (94). Some tools are also available to predict metastatic outcomes, such as Decipher tissue-based genomic classifier. Based on 22 RNA biomarkers, Decipher has proven its efficacy in predicting the 10 years' distant metastasis (95) and prostate cancer-specific mortality (96). Molecular biomarkers thus hold the potential to select patients for appropriate treatment and thus reduce overtreatment and toxicities. One of the challenges in the future will be to identify patients with indolent disease, who will achieve satisfactory results with MDT alone, from patients with aggressive, high-risk polymetastatic disease who may benefit from the addition of systemic therapy. Recent advances in 
TABLE 2 | Prospective randomized trials evaluating patient outcomes after restaging PET/CT in prostate cancer patients with biochemical recurrence after radical prostatectomy.

\begin{tabular}{|c|c|c|c|c|}
\hline Trial & $\mathbf{N}$ & Study design & $\begin{array}{l}\text { Primary end- } \\
\text { point }\end{array}$ & Results \\
\hline $\begin{array}{l}\text { Jani et al. (53) } \\
\text { EMPIRE I - } \\
\text { NCT01666808 }\end{array}$ & 165 & $\begin{array}{l}\text { Phase II/III randomized: } \\
{ }^{18} \mathrm{~F} \text {-Fluciclovine guided-treatment vs SOC }\end{array}$ & $\begin{array}{l}\text { 3-yr event-free } \\
\text { survival }\end{array}$ & $\begin{array}{l}\text { - 3-yr event-free survival: } 63 \% \text { SOC vs } 75.5 \%{ }^{18} \mathrm{~F} \text { - } \\
\text { Fluciclovine PET/CT } \\
\text { - } 35 \% \text { treatment change with }{ }^{18} \mathrm{~F} \text {-Fluciclovine PET/ } \\
\text { CT }\end{array}$ \\
\hline $\begin{array}{l}\text { EMPIRE II - } \\
\text { NCT03762759 }\end{array}$ & $\begin{array}{l}\text { 140, } \\
\text { recruiting }\end{array}$ & $\begin{array}{l}\text { Phase II randomized: } \\
{ }^{18} \text { F-Fluciclovine vs }{ }^{68} \text { Ga-PSMA }\end{array}$ & $\begin{array}{l}\text { Disease-free } \\
\text { survival }\end{array}$ & - Ongoing trial \\
\hline NCT03525288 & 129 & $\begin{array}{l}\text { Phase II randomized: }{ }^{18} \mathrm{~F} \text {-DCFPyL PSMA guided- } \\
\text { treatment vs SOC }\end{array}$ & 5-yr FFS & - Primary endpoint analysis ongoing \\
\hline NCT04794777 & $\begin{array}{l}450, \\
\text { recruiting }\end{array}$ & $\begin{array}{l}\text { Phase III randomized: } \\
\text { PSMA (either }{ }^{68} \mathrm{Ga} \text { or }{ }^{18} \mathrm{~F}-1007 \text { ) guided-treatment vs } \\
\text { SOC }\end{array}$ & PFS & - Ongoing trial \\
\hline $\begin{array}{l}\text { PATRON - } \\
\text { NCTO4557501 } \\
\text { (definitive and salvage } \\
\text { setting) }\end{array}$ & $\begin{array}{l}\text { 776, } \\
\text { recruiting }\end{array}$ & $\begin{array}{l}\text { Phase III randomized: }{ }^{18} \mathrm{~F} \text {-DCFPyL PSMA guided- } \\
\text { treatment vs SOC }\end{array}$ & 5-yr FFS & - Ongoing trial \\
\hline
\end{tabular}

PSMA, prostate specific membrane antigen; SOC, standard of care; SRT, salvage radiotherapy; bRFS, biochemical relapse free-survival; RP, radical prostatectomy; MDT, Metastasis Directed Therapy; PFS, Progression Free Survival; LHRH, Luteinizing Hormone Releasing Hormone; FFS, Failure-Free Survival.

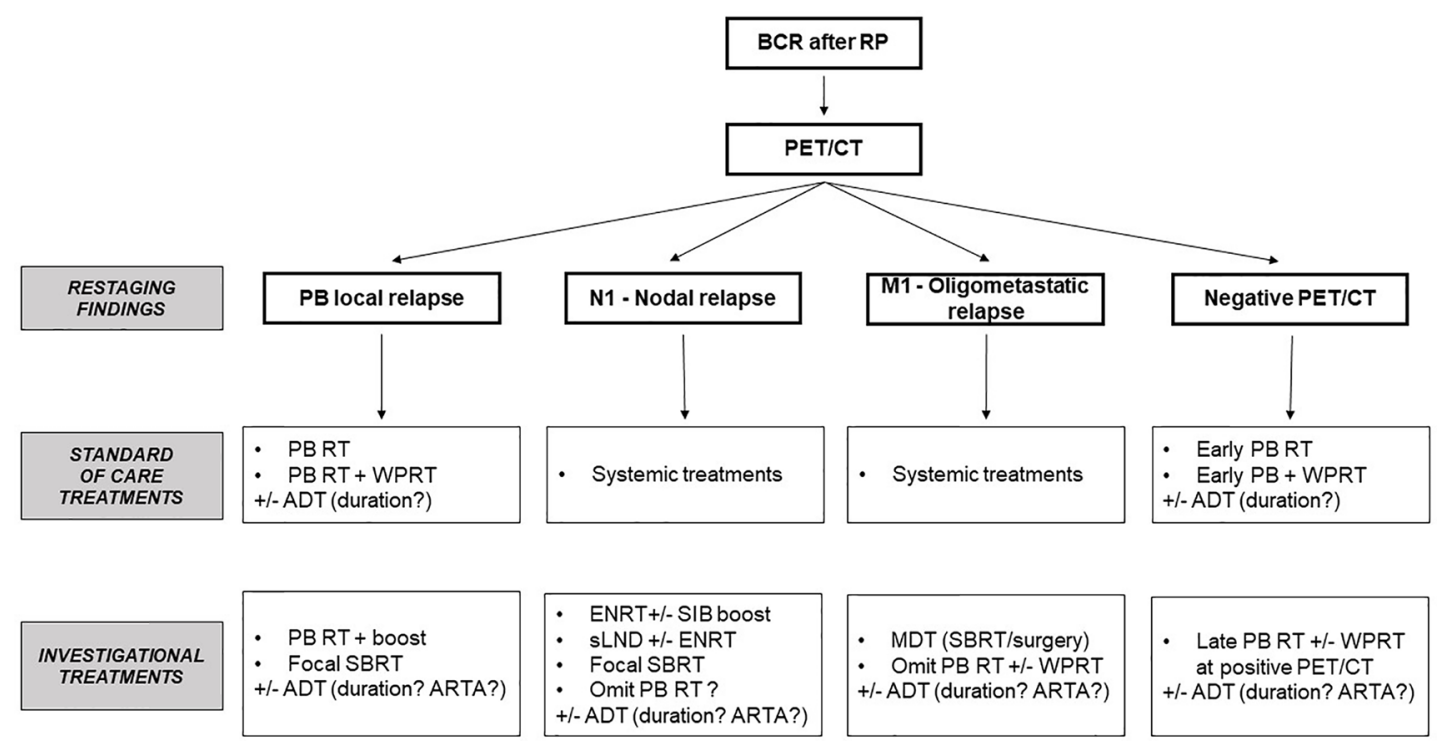

FIGURE 3 | Potential therapeutic options based on PET/CT restaging findings. BCR, biochemical relapse; RP, radical prostatectomy; RT, radiotherapy; PB, prostate bed; WPRT, whole pelvic radiation therapy; SBRT, stereotactic body radiation therapy; ADT, androgen-deprivation therapy; ENRT, elective nodal radiotherapy; SIB, simultaneous integrated boost; sLND, salvage lymph node dissection; MDT, metastasis-directed therapy; ARTA, androgen receptor targeted agents. 
biology, such as implementation of Whole-Exome Sequencing in routine practice or understanding of microRNA pathways will probably allow us to obtain much more information on this point.

In parallel, improvements in performance of next-generation imaging including use of new prostate-specific tracers $(49,97$, 98), implementation of radiomics features (99) and artificial intelligence techniques (100), and new PET imaging tools providing superior spatial and temporal resolution compared to commercially available PET scanners will undoubtedly play increasing roles in defining the presence and extent of relapsing disease and will promote the development and use of precision therapies in patients with relapsing prostate cancer.

\section{CONCLUSIONS}

PET/CT is an emerging imaging modality with better accuracy than conventional imaging for restaging of prostate cancer patients in BCR after RP. Accurate detection of relapsing disease has led to management changes in hopes of improving the therapeutic ratio of this patient population, but to date with little evidence to support this change. Intensification of treatment strategies with delivery of focal boosts to the macroscopic relapse, expansion of target volumes to encompass areas usually not targeted by usual guidelines, addition of systemic treatments, or

\section{REFERENCES}

1. Freedland SJ, Humphreys E, Mangold LA, Eisenberg M, Dorey FJ, Walsh PC, et al. Risk of Prostate Cancer-Specific Mortality Following Biochemical Recurrence After Radical Prostatectomy. JAMA (2005) 294(4):433-9. doi: $10.1001 /$ jama2944433

2. Hull G, Rabbani F, Abbas F, Wheeler T, Kattan M, Scardino P. Cancer Control With Radical Prostatectomy Alone in 1,000 Consecutive Patients. J Urol (2002) 167(2 Pt 1):528-34. doi: 10.1097/00005392-200202000-00018

3. Roehl KA, Han M, Ramos CG, Antenor JA, Catalona WJ. Cancer Progression and Survival Rates Following Anatomical Radical Retropubic Prostatectomy in 3,478 Consecutive Patients: Long-Term Results. J Urol (2004) 172(3):910-4. doi: 10.1097/01.ju.0000134888.22332.bb

4. Mottet N, van den Bergh RCN, Briers E, Van den Broeck T, Cumberbatch MG, De Santis M, et al. EAU-EANM-ESTRO-ESUR-SIOG Guidelines on Prostate Cancer-2020 Update. Part 1: Screening, Diagnosis, and Local Treatment With Curative Intent. Eur Urol (2021) 79(2):243-62. doi: 10.1016/j.eururo. 2020.09.042

5. Stephenson AJ, Scardino P, Eastham JA, Bianco FJ Jr, Dotan ZA, Fearn PA, et al. Preoperative Nomogram Predicting the 10-Year Probability of Prostate Cancer Recurrence After Radical Prostatectomy. J Natl Cancer Inst (2006) 98 (10):715-7. doi: 10.1093/jnci/djj190

6. Thompson IM, Tangen CM, Paradelo J, Lucia MS, Miller G, Troyer D, et al. Adjuvant Radiotherapy for Pathological T3N0M0 Prostate Cancer Significantly Reduces Risk of Metastases and Improves Survival: Long-Term Follow-Up of a Randomized Clinical Trial. J Urol (2009) 181(3):956-62. doi: 10.1016/j.juro. 2008.11.032

7. Bolla M, van Poppel H, Tombal B, Vekemans K, Da Pozzo L, de Reijke TM, et al. Postoperative Radiotherapy After Radical Prostatectomy for High-Risk Prostate Cancer: Long-Term Results of a Randomised Controlled Trial (EORTC Trial 22911). Lancet (2012) 380(9858):2018-27. doi: 10.1016/S01406736(12)61253-7

8. Wiegel T, Bartkowiak D, Bottke D, Bronner C, Steiner U, Siegmann A, et al. Adjuvant Radiotherapy Versus Wait-and-See After Radical Prostatectomy: 10- change in treatment intent remain open issues requiring further investigations. Ongoing trials assessing the impact of PET/CTguided SRT will certainly help to better determine the clinical impact on long-term outcomes of integrating metabolic imaging in the restaging and therapeutic workflow of patients recurring after RP and candidates to salvage RT.

\section{AUTHOR CONTRIBUTIONS}

JG, PS, IL, CM, and TZ were involved in the study design and concept. JG, CM, and TZ were involved in the drafting of the manuscript. All authors contributed in the review and editing of the manuscript. All authors contributed to the article and approved the submitted version.

\section{FUNDING}

This work was partially funded by a Swiss Prostate Cancer Award grant from the Movember Foundation (NCT03569241 trial), a grant from the "Fondation Prive" of Geneva University Hospital (RC06-01) and the Swiss National Science Foundation (project 320030_182366).
Year Follow-Up of the ARO 96-02/AUO AP 09/95 Trial. Eur Urol (2014) 66 (2):243-50. doi: 10.1016/j.eururo.2014.03.011

9. Hackman G TK, Taari K, Tammela T, Matikainen M, Kouri M, Joensuu T, et al. Randomised Trial of Adjuvant Radiotherapy Following Radical Prostatectomy Versus Radical Prostatectomy Alone in Prostate Cancer Patients With Positive Margins or Extracapsular Extension. Eur Urol (2019) 76(5):586-95. doi: 10.1016/jeururo201907001

10. Tilki D, Chen M-H, Wu J, Huland H, Graefen M, Wiegel T, et al. Adjuvant Versus Early Salvage Radiation Therapy for Men at High Risk for Recurrence Following Radical Prostatectomy for Prostate Cancer and the Risk of Death. J Clin Oncol (2021) 39(20):2284-93. doi: 10.1200/JCO.20.03714

11. Kneebone A, Fraser-Browne C, Duchesne GM, Fisher R, Frydenberg M, Herschtal A, et al. Adjuvant Radiotherapy Versus Early Salvage Radiotherapy Following Radical Prostatectomy (TROG 08.03/ANZUP RAVES): A Randomised, Controlled, Phase 3, Non-Inferiority Trial. Lancet Oncol (2020) 21(10):1331-40. doi: 10.1016/S1470-2045(20)30456-3

12. Vale CL, Fisher D, Kneebone A, Parker C, Pearse M, Richaud P, et al. Adjuvant or Early Salvage Radiotherapy for the Treatment of Localised and Locally Advanced Prostate Cancer: A Prospectively Planned Systematic Review and Meta-Analysis of Aggregate Data. Lancet (2020) 396 (10260):1422-31. doi: 10.1016/S0140-6736(20)31952-8

13. Sargos P, Chabaud S, Latorzeff I, Magné N, Benyoucef A, Supiot S, et al. Adjuvant Radiotherapy Versus Early Salvage Radiotherapy Plus Short-Term Androgen Deprivation Therapy in Men With Localised Prostate Cancer After Radical Prostatectomy (GETUG-AFU 17): A Randomised, Phase 3 Trial. Lancet Oncol (2020) 21(10):1341-52. doi: 10.1016/S1470-2045(20) 30454-X

14. Parker CC, Clarke NW, Cook AD, Kynaston HG, Petersen PM, Catton C, et al. Timing of Radiotherapy After Radical Prostatectomy (RADICALS-RT): A Randomised, Controlled Phase 3 Trial. Lancet (2020) 396(10260):1413-21. doi: 10.1016/S0140-6736(20)31553-1

15. King CR. The Timing of Salvage Radiotherapy After Radical Prostatectomy: A Systematic Review. Int J Radiat Oncol Biol Phys (2012) 84(1):104-11. doi: 10.1016/j.ijrobp.2011.10.069 
16. Robin S, Jolicoeur M, Palumbo S, Zilli T, Crehange G, De Hertogh O, et al. Prostate Bed Delineation Guidelines for Postoperative Radiation Therapy: On Behalf Of The Francophone Group of Urological Radiation Therapy. Int J Radiat Oncol Biol Phys (2021) 109(5):1243-53. doi: 10.1016/j.ijrobp.2020.11.010

17. Poortmans P, Bossi A, Vandeputte K, Bosset M, Miralbell R, Maingon P, et al. Guidelines for Target Volume Definition in Post-Operative Radiotherapy for Prostate Cancer, on Behalf of the EORTC Radiation Oncology Group. Radiother Oncol (2007) 84(2):121-7. doi: 10.1016/j.radonc.2007.07.017

18. Hall WA, Paulson E, Davis BJ, Spratt DE, Morgan TM, Dearnaley D, et al. NRG Oncology Updated International Consensus Atlas on Pelvic Lymph Node Volumes for Intact and Postoperative Prostate Cancer. Int J Radiat Oncol Biol Phys (2021) 109(1):174-85. doi: 10.1016/j.ijrobp.2020.08.034

19. Hovels AM, Heesakkers RA, Adang EM, Jager GJ, Strum S, Hoogeveen YL, et al. The Diagnostic Accuracy of CT and MRI in the Staging of Pelvic Lymph Nodes in Patients With Prostate Cancer: A Meta-Analysis. Clin Radiol (2008) 63(4):387-95. doi: 10.1016/j.crad.2007.05.022

20. Shen G, Deng H, Hu S, Jia Z. Comparison of Choline-PET/CT, MRI, SPECT, and Bone Scintigraphy in the Diagnosis of Bone Metastases in Patients With Prostate Cancer: A Meta-Analysis. Skeletal Radiol (2014) 43(11):1503-13. doi: 10.1007/s00256-014-1903-9

21. Fanti S, Minozzi S, Castellucci P, Balduzzi S, Herrmann K, Krause BJ, et al. PET/CT With (11)C-Choline for Evaluation of Prostate Cancer Patients With Biochemical Recurrence: Meta-Analysis and Critical Review of Available Data. Eur J Nucl Med Mol Imaging (2016) 43(1):55-69. doi: 10.1007/ s00259-015-3202-7

22. Yoshimoto M, Waki A, Obata A, Furukawa T, Yonekura Y, Fujibayashi Y. Radiolabeled Choline as a Proliferation Marker: Comparison With Radiolabeled Acetate. Nucl Med Biol (2004) 31(7):859-65. doi: 10.1016/ j.nucmedbio.2004.05.002

23. Beheshti M, Vali R, Waldenberger P, Fitz F, Nader M, Hammer J, et al. The Use of F-18 Choline PET in the Assessment of Bone Metastases in Prostate Cancer: Correlation With Morphological Changes on CT. Mol Imaging Biol (2010) 12(1):98-107. doi: 10.1007/s11307-009-0239-7

24. Schwarzenbock S, Souvatzoglou M, Krause BJ. Choline PET and PET/CT in Primary Diagnosis and Staging of Prostate Cancer. Theranostics (2012) 2 (3):318-30. doi: 10.7150/thno.4008

25. Evangelista L, Cimitan M, Hodolic M, Baseric T, Fettich J, Borsatti E. The Ability of 18F-Choline PET/CT to Identify Local Recurrence of Prostate Cancer. Abdom Imaging (2015) 40(8):3230-7. doi: 10.1007/s00261-015-0547-0

26. Axumin (Fluciclovine F 18) Injection. U.S. Food and Drug Administration. Available at: https://www.accessdata.fda.gov/drugsatfda_docs/nda/2016/ 208054Orig1s000TOC.cfm (Accessed January 28).

27. Andriole GL, Kostakoglu L, Chau A, Duan F, Mahmood U, Mankoff DA, et al. The Impact of Positron Emission Tomography With 18F-Fluciclovine on the Treatment of Biochemical Recurrence of Prostate Cancer: Results From the LOCATE Trial. J Urol (2019) 201(2):322-31. doi: 10.1016/j.juro.2018.08.050

28. Gusman M, Aminsharifi JA, Peacock JG, Anderson SB, Clemenshaw MN, Banks KP. Review of (18)F-Fluciclovine PET for Detection of Recurrent Prostate Cancer. Radiographics (2019) 39(3):822-41. doi: 10.1148/rg.2019180139

29. Nanni C, Schiavina R, Brunocilla E, Boschi S, Borghesi M, Zanoni L, et al. 18fFluciclovine PET/CT for the Detection of Prostate Cancer Relapse: A Comparison to 11C-Choline PET/Ct. Clin Nucl Med (2015) 40(8):e386-91. doi: 10.1097/RLU.0000000000000849

30. Scarsbrook AF, Bottomley D, Teoh EJ, Bradley KM, Payne H, Afaq A, et al. Effect of (18)F-Fluciclovine Positron Emission Tomography on the Management of Patients With Recurrence of Prostate Cancer: Results From the FALCON Trial. Int J Radiat Oncol Biol Phys (2020) 107(2):316-24. doi: 10.1016/j.ijrobp.2020.01.050

31. Bois F, Noirot C, Dietemann S, Mainta IS, Zilli T, Garibotto V, et al. [68ga]GaPSMA-11 in Prostate Cancer: A Comprehensive Review. Am J Nucl Med Mol Imaging (2020) 10(6):349-74:eCollection 2020.

32. Morris MJ, Rowe SP, Gorin MA, Saperstein L, Pouliot F, Josephson D, et al. Diagnostic Performance of (18)F-DCFPyL-PET/CT in Men With Biochemically Recurrent Prostate Cancer: Results From the CONDOR Phase IIIMulticenter Study. Clin Cancer Res (2021) 27(13):3674-82. doi: 10.1158/1078-0432.CCR-20-4573

33. Hofman MS, Lawrentschuk N, Francis RJ, Tang C, Vela I, Thomas P, et al. Prostate-Specific Membrane Antigen PET-CT in Patients With High-Risk
Prostate Cancer Before Curative-Intent Surgery or Radiotherapy (proPSMA): A Prospective, Randomised, Multicentre Study. Lancet (2020) 395 (10231):1208-16. doi: 10.1016/S0140-6736(20)30314-7

34. Roach PJ, Francis R, Emmett L, Hsiao E, Kneebone A, Hruby G, et al. The Impact of (68)Ga-PSMA PET/CT on Management Intent in Prostate Cancer: Results of an Australian Prospective Multicenter Study. J Nucl Med (2018) 59 (1):82-8. doi: 10.2967/jnumed.117.197160

35. Zacho H, Ravn S, Afshar-Oromieh A, Fledelius J, Ejlersen J, Petersen L. Added Value of 68 Ga-PSMA PET/CT for the Detection of Bone Metastases in Patients With Newly Diagnosed Prostate Cancer and a Previous 99m Tc Bone Scintigraphy. EJNMMI Res (2020) 10(1):31. doi: 10.1186/s13550-020-00618-0

36. Stephenson AJ, Scardino PT, Kattan MW, Pisansky TM, Slawin KM, Klein EA, et al. Predicting the Outcome of Salvage Radiation Therapy for Recurrent Prostate Cancer After Radical Prostatectomy. J Clin Oncol (2007) 25 (15):2035-41. doi: 10.1200/JCO.2006.08.9607

37. Park JS, Park W, Pyo HR, Park BK, Park SY, Choi HY, et al. Suggestion for the Prostatic Fossa Clinical Target Volume in Adjuvant or Salvage Radiotherapy After a Radical Prostatectomy. Radiother Oncol (2014) 110(2):240-4. doi: 10.1016/j.radonc.2014.01.001

38. Swanson GP, Hussey MA, Tangen CM, Chin J, Messing E, Canby-Hagino E, et al. Predominant Treatment Failure in Post Prostatectomy Patients Is Local: Analysis of Patterns of Treatment Failure in SWOG 8794. J Clin Oncol (2007) 25(16):2225-9. doi: 10.1200/JCO.2006.09.6495

39. Michalski JM, Lawton C, El Naqa I, Ritter M, O'Meara E, Seider MJ, et al. Development of RTOG Consensus Guidelines for the Definition of the Clinical Target Volume for Postoperative Conformal Radiation Therapy for Prostate Cancer. Int J Radiat Oncol Biol Phys (2010) 76(2):361-8. doi: 10.1016/j.ijrobp.2009.02.006

40. Sidhom MA, Kneebone AB, Lehman M, Wiltshire KL, Millar JL, Mukherjee RK, et al. Post-Prostatectomy Radiation Therapy: Consensus Guidelines of the Australian and New Zealand Radiation Oncology Genito-Urinary Group. Radiother Oncol (2008) 88(1):10-9. doi: 10.1016/j.radonc.2008.05.006

41. Wiltshire KL, Brock KK, Haider MA, Zwahlen D, Kong V, Chan E, et al. Anatomic Boundaries of the Clinical Target Volume (Prostate Bed) After Radical Prostatectomy. Int J Radiat Oncol Biol Phys (2007) 69(4):1090-9. doi: 10.1016/j.ijrobp.2007.04.068

42. El Kabbaj O, Robin P, Bourhis D, Dissaux G, Rosenfelder N, Valeri A, et al. Target Definition in Salvage Postoperative Radiotherapy for Prostate Cancer: 18F-Fluorocholine PET/CT Assessment of Local Recurrence. Acta Oncol (2018) 57(3):375-81. doi: 10.1080/0284186X.2017.1385843

43. Dal Pra A, Panje C, Zilli T, Arnold W, Brouwer K, Garcia H, et al. Salvage Radiotherapy for Macroscopic Local Recurrences After Radical Prostatectomy : A National Survey on Patterns of Practice. Strahlenther Onkol (2018) 194(1):916. doi: 10.1007/s00066-017-1172-3

44. Pollack A, Karrison TG, Balogh AG, Low D, Bruner DW, Wefel JS, et al. Short Term Androgen Deprivation Therapy Without or With Pelvic Lymph Node Treatment Added to Prostate Bed Only Salvage Radiotherapy: The NRG Oncology/RTOG 0534 SPPORT Trial. Int J Radiat Oncol Biol Phys (2018) 102 (5):1605. doi: 10.1016/j.ijrobp.2018.08.052

45. Shipley WU, Seiferheld W, Lukka HR, Major PP, Heney NM, Grignon DJ, et al. Radiation With or Without Antiandrogen Therapy in Recurrent Prostate Cancer. N Engl J Med (2017) 376(5):417-28. doi: 10.1056/NEJMoa1607529

46. Carrie C, Magné N, Burban-Provost P, Sargos P, Latorzeff I, Lagrange J-L, et al. Short-Term Androgen Deprivation Therapy Combined With Radiotherapy as Salvage Treatment After Radical Prostatectomy for Prostate Cancer (GETUG-AFU 16): A 112-Month Follow-Up of a Phase 3, Randomised Trial. Lancet Oncol (2019) 20(12):1740-9. doi: 10.1016/S14702045(19)30486-3

47. Francolini G, Jereczek-Fossa BA, Di Cataldo V, Simontacchi G, Marvaso G, Zerella MA, et al. Stereotactic Radiotherapy for Prostate Bed Recurrence After Prostatectomy, a Multicentric Series. BJU Int (2020) 125(3):417-25. doi: 10.1111/bju.14924

48. D'Angelillo RM, Sciuto R, Ramella S, Papalia R, Jereczek-Fossa BA, Trodella LE, et al. (1)(8)F-Choline Positron Emission Tomography/Computed Tomography-Driven High-Dose Salvage Radiation Therapy in Patients With Biochemical Progression After Radical Prostatectomy: Feasibility Study in 60 Patients. Int J Radiat Oncol Biol Phys (2014) 90(2):296-302. doi: 10.1016/j.ijrobp.2014.05.050 
49. Eiber M, Maurer T, Souvatzoglou M, Beer AJ, Ruffani A, Haller B, et al. Evaluation of Hybrid (6)(8)Ga-PSMA Ligand PET/CT in 248 Patients With Biochemical Recurrence After Radical Prostatectomy. J Nucl Med (2015) 56 (5):668-74. doi: 10.2967/jnumed.115.154153

50. Perera M, Papa N, Christidis D, Wetherell D, Hofman MS, Murphy DG, et al. Sensitivity, Specificity, and Predictors of Positive (68)Ga-Prostate-Specific Membrane Antigen Positron Emission Tomography in Advanced Prostate Cancer: A Systematic Review and Meta-Analysis. Eur Urol (2016) 70(6):92637. doi: 10.1016/j.eururo.2016.06.021

51. Calais J, Ceci F, Eiber M, Hope TA, Hofman MS, Rischpler C, et al. 18FFluciclovine PET-CT and 68Ga-PSMA-11 PET-CT in Patients With Early Biochemical Recurrence After Prostatectomy: A Prospective, Single-Centre, Single-Arm, Comparative Imaging Trial. Lancet Oncol (2019) 20(9):1286-94. doi: 10.1016/S1470-2045(19)30415-2

52. Pernthaler B, Kulnik R, Gstettner C, Salamon S, Aigner RM, Kvaternik H. A Prospective Head-To-Head Comparison of 18F-Fluciclovine With 68gaPSMA-11 in Biochemical Recurrence of Prostate Cancer in PET/Ct. Clin Nucl Med (2019) 44(10):e566-e73. doi: 10.1097/RLU.0000000000002703

53. Jani A, Schreibmann E, Goyal S, Raghuveer H, Hershatter B, Rossi P, et al. Initial Report of a Randomized Trial Comparing Conventional- vs Conventional Plus Fluciclovine (18F) PET/CT Imaging- Guided PostProstatectomy Radiotherapy for Prostate Cancer. Int J Radiat Oncol Biol Phys (2020) 108(5):1397. doi: 10.1016/j.ijrobp.2020.09.018

54. Jani A, Schreibmann E, Goyal S, Halkar R, Hershatter B, Rossi P, et al. 18 FFluciclovine-PET/CT Imaging Versus Conventional Imaging Alone to Guide Postprostatectomy Salvage Radiotherapy for Prostate Cancer (EMPIRE-1): A Single Centre, Open-Label, Phase 2/3 Randomised Controlled Trial. Lancet (2021) 397(10288):1895-904. doi: 10.1016/S0140-6736(21)00581-X

55. Calais J, Czernin J, Cao M, Kishan AU, Hegde JV, Shaverdian N, et al. (68)GaPSMA-11 PET/CT Mapping of Prostate Cancer Biochemical Recurrence After Radical Prostatectomy in 270 Patients With a PSA Level of Less Than $1.0 \mathrm{Ng} /$ Ml: Impact on Salvage Radiotherapy Planning. J Nucl Med (2018) 59(2):2307. doi: $10.2967 /$ jnumed.117.201749

56. Brand DH, Parker JI, Dearnaley DP, Eeles R, Huddart R, Khoo V, et al. Patterns of Recurrence After Prostate Bed Radiotherapy. Radiother Oncol (2019) 141:174-80. doi: 10.1016/j.radonc.2019.09.007

57. Jilg CA, Drendel V, Rischke HC, Beck T, Vach W, Schaal K, et al. Diagnostic Accuracy of Ga-68-HBED-CC-PSMA-Ligand-PET/CT Before Salvage Lymph Node Dissection for Recurrent Prostate Cancer. Theranostics (2017) 7 (6):1770-80. doi: 10.7150/thno.18421

58. Murthy V, Maitre P, Bhatia J, Kannan S, Krishnatry R, Prakash G, et al. Late Toxicity and Quality of Life With Prostate Only or Whole Pelvic Radiation Therapy in High Risk Prostate Cancer (POP-RT): A Randomised Trial. Radiother Oncol (2020) 145:71-80. doi: 10.1016/j.radonc.2019.12.006

59. De Bruycker A, Lambert B, Claeys T, Delrue L, Mbah C, De Meerleer G, et al. Prevalence and Prognosis of Low-Volume, Oligorecurrent, HormoneSensitive Prostate Cancer Amenable to Lesion Ablative Therapy. BJU Int (2017) 120(6):815-21. doi: 10.1111/bju.13938

60. Meijer HJ, van Lin EN, Debats OA, Witjes JA, Span PN, Kaanders JH, et al. High Occurrence of Aberrant Lymph Node Spread on Magnetic Resonance Lymphography in Prostate Cancer Patients With a Biochemical Recurrence After Radical Prostatectomy. Int J Radiat Oncol Biol Phys (2012) 82(4):140510. doi: 10.1016/j.ijrobp.2011.04.054

61. Abu-Gheida I, Bathala TK, Maldonado JA, Khan M, Anscher MS, Frank SJ, et al. Increased Frequency of Mesorectal and Perirectal LN Involvement in T4 Prostate Cancers. Int J Radiat Oncol Biol Phys (2020) 107(5):982-5. doi: 10.1016/j.ijrobp.2020.04.025

62. Fodor A, Berardi G, Fiorino C, Picchio M, Busnardo E, Kirienko M, et al. Toxicity and Efficacy of Salvage Carbon 11-Choline Positron Emission Tomography/Computed Tomography-Guided Radiation Therapy in Patients With Lymph Node Recurrence of Prostate Cancer. BJU Int (2017) 119(3):406-13. doi: 10.1111/bju.13510

63. Vaugier L, Palpacuer C, Rio E, Goineau A, Pasquier D, Buthaud X, et al. Early Toxicity of a Phase 2 Trial of Combined Salvage Radiation Therapy and Hormone Therapy in Oligometastatic Pelvic Node Relapses of Prostate Cancer (OLIGOPELVIS GETUG P07). Int J Radiat Oncol Biol Phys (2019) 103(5):1061-7. doi: 10.1016/j.jirobp.2018.12.020
64. Supiot S, Vaugier L, Pasquier D, Buthaud X, Magne N, Peiffert D, et al. OLIGOPELVIS GETUG P07, a Multicenter Phase II Trial of Combined HighDose Salvage Radiotherapy and Hormone Therapy in Oligorecurrent Pelvic Node Relapses in Prostate Cancer. Eur Urol (2021) S0302-2838(21)01816-9. doi: 10.1016/j.eururo.2021.06.010

65. Decaestecker K, Meerleer GD, Ameye F, Fonteyne V, Lambert B, Joniau S, et al. Surveillance or Metastasis-Directed Therapy for OligoMetastatic Prostate Cancer Recurrence (STOMP): Study Protocol for a Randomized Phase II Trial. BMC Cancer (2014) 14:671. doi: 10.1186/1471-2407-14-671

66. Phillips R, Shi WY, Deek M, Radwan N, Lim SJ, Antonarakis ES, et al. Outcomes of Observation vs Stereotactic Ablative Radiation for Oligometastatic Prostate Cancer: The ORIOLE Phase 2 Randomized Clinical Trial. JAMA Oncol (2020) 6(5):650-9. doi: 10.1001/jamaoncol. 2020.0147

67. Achard V, Bottero M, Rouzaud M, Lancia A, Scorsetti M, Filippi AR, et al. Radiotherapy Treatment Volumes for Oligorecurrent Nodal Prostate Cancer: A Systematic Review. Acta Oncol (2020) 59(10):1224-34. doi: 10.1080/ 0284186X.2020.1775291

68. De Bleser E, Jereczek-Fossa BA, Pasquier D, Zilli T, Van As N, Siva S, et al. Metastasis-Directed Therapy in Treating Nodal Oligorecurrent Prostate Cancer: A Multi-Institutional Analysis Comparing the Outcome and Toxicity of Stereotactic Body Radiotherapy and Elective Nodal Radiotherapy. Eur Urol (2019) 76(6):732-9. doi: 10.1016/j.eururo.2019.07.009

69. Siriwardana A, Thompson J, van Leeuwen PJ, Doig S, Kalsbeek A, Emmett L, et al. Initial Multicentre Experience of (68) Gallium-PSMA PET/CT Guided Robot-Assisted Salvage Lymphadenectomy: Acceptable Safety Profile But Oncological Benefit Appears Limited. BJU Int (2017) 120(5):673-81. doi: 10.1111/bju.13919

70. Ploussard G, Gandaglia G, Borgmann H, de Visschere P, Heidegger I, Kretschmer A, et al. Salvage Lymph Node Dissection for Nodal Recurrent Prostate Cancer: A Systematic Review. Eur Urol (2019) 76(4):493-504. doi: 10.1016/jeururo201810041

71. Ost P, Jereczek-Fossa BA, Van As N, Zilli T, Tree A, Henderson D, et al. Pattern of Progression After Stereotactic Body Radiotherapy for Oligometastatic Prostate Cancer Nodal Recurrences. Clin Oncol ( $R$ Coll Radiol) (2016) 28(9):e115-20. doi: 10.1016/j.clon.2016.04.040

72. De Bruycker A, Spiessens A, Dirix P, Koutsouvelis N, Semac I, Liefhooghe N, et al. PEACE V - Salvage Treatment of OligoRecurrent Nodal Prostate Cancer Metastases (STORM): A Study Protocol for a Randomized Controlled Phase II Trial. BMC Cancer (2020) 20(1):406. doi: 10.1186/s12885-020-06911-4

73. Zilli T, Dirix P, Heikkilä R, Liefhooghe N, Siva S, Gomez-Iturriaga A, et al. The Multicenter, Randomized, Phase 2 PEACE V-STORM Trial: Defining the Best Salvage Treatment for Oligorecurrent Nodal Prostate Cancer Metastases. Eur Urol Focus (2021) 7:241-4. doi: 10.1016/jeuf202012010

74. Schiller K, Sauter K, Dewes S, Eiber M, Maurer T, Gschwend J, et al. Patterns of Failure After Radical Prostatectomy in Prostate Cancer - Implications for Radiation Therapy Planning After (68)Ga-PSMA-PET Imaging. Eur J Nucl Med Mol Imaging (2017) 44(10):1656-62. doi: 10.1007/s00259-017-3746-9

75. Calais J, Kishan AU, Cao M, Fendler WP, Eiber M, Herrmann K, et al. Potential Impact of (68)Ga-PSMA-11 PET/CT on the Planning of Definitive Radiation Therapy for Prostate Cancer. J Nucl Med (2018) 59(11):1714-21. doi: 10.2967/jnumed.118.209387

76. Sundahl N, Gillessen S, Sweeney C, Ost P. When What You See Is Not Always What You Get: Raising the Bar of Evidence for New Diagnostic Imaging Modalities. Eur Urol (2021) 79(5):565-7. doi: 10.1016/j.eururo.2020.07.029

77. Hope TA, Goodman JZ, Allen IE, Calais J, Fendler WP, Carroll PR. MetaAnalysis of (68)Ga-PSMA-11 PET Accuracy for the Detection of Prostate Cancer Validated by Histopathology. J Nucl Med (2019) 60(6):786-93. doi: 10.2967/jnumed.118.219501

78. Kothari G, Ost P, Cheung P, Blanchard P, Tree AC, van As NJ, et al. Trends in Management of Oligometastatic Hormone-Sensitive Prostate Cancer. Curr Oncol Rep (2019) 21(5):43. doi: 10.1007/s11912-019-0791-5

79. Palma DA, Olson R, Harrow S, Gaede S, Louie AV, Haasbeek C, et al. Stereotactic Ablative Radiotherapy for the Comprehensive Treatment of Oligometastatic Cancers: Long-Term Results of the SABR-COMET Phase II Randomized Trial. J Clin Oncol (2020) 38(25):2830-8. doi: 10.1200/ JCO2000818 
80. Lancia A, Zilli T, Achard V, Dirix P, Everaerts W, Gomez-Iturriaga A, et al. Oligometastatic Prostate Cancer: The Game Is Afoot. Cancer Treat Rev (2019) 73:84-90. doi: 10.1016/j.ctrv.2019.01.005

81. Gundem G, Van Loo P, Kremeyer B, Alexandrov LB, Tubio JMC, Papaemmanuil E, et al. The Evolutionary History of Lethal Metastatic Prostate Cancer. Nature (2015) 520(7547):353-7. doi: 10.1038/nature14347

82. Hong MK, Macintyre G, Wedge DC, Van Loo P, Patel K, Lunke S, et al. Tracking the Origins and Drivers of Subclonal Metastatic Expansion in Prostate Cancer. Nat Commun (2015) 6:6605. doi: 10.1038/ncomms7605

83. Vilela RA, Navarro NF, Faria ET, Ferreira EB, Ruzza RZ, Gadia R, et al. Use of Stereotactic Body Radiation Therapy for Oligometastatic Recurrent Prostate Cancer: A Systematic Review. J Med Imaging Radiat Oncol (2018) 62(5):692706. doi: 10.1111/1754-9485.12747

84. Kyriakopoulos C, Chen Y, Carducci M, Liu G, Jarrard DF, Hahn N, et al. Chemohormonal Therapy in Metastatic Hormone-Sensitive Prostate Cancer: Long-Term Survival Analysis of the Randomized Phase III E3805 CHAARTED Trial. J Clin Oncol (2018) 36(11):1080-7. doi: 10.1200/JCO2017753657

85. Sweeney CJ, Chen YH, Carducci M, Liu G, Jarrard DF, Eisenberger M, et al. Chemohormonal Therapy in Metastatic Hormone-Sensitive Prostate Cancer. N Engl J Med (2015) 373(8):737-46. doi: 10.1056/NEJMoa1503747

86. Fizazi K, Tran N, Fein L, Matsubara N, Rodriguez-Antolin A, Alekseev BY, et al. Abiraterone Plus Prednisone in Metastatic, Castration-Sensitive Prostate Cancer. N Engl J Med (2017) 377(4):352-60. doi: 10.1056/NEJMoa1704174

87. Abugharib A, Jackson WC, Tumati V, Dess RT, Lee JY, Zhao SG, et al. Very Early Salvage Radiotherapy Improves Distant Metastasis-Free Survival. J Urol (2017) 197(3 Pt 1):662-8. doi: 10.1016/j.juro.2016.08.106

88. Fossati N, Karnes RJ, Cozzarini C, Fiorino C, Gandaglia G, Joniau S, et al. Assessing the Optimal Timing for Early Salvage Radiation Therapy in Patients With Prostate-Specific Antigen Rise After Radical Prostatectomy. Eur Urol (2016) 69(4):728-33. doi: 10.1016/j.eururo.2015.10.009

89. Emmett L, van Leeuwen PJ, Nandurkar R, Scheltema MJ, Cusick T, Hruby G, et al. Treatment Outcomes From (68)Ga-PSMA PET/CT-Informed Salvage Radiation Treatment in Men With Rising PSA After Radical Prostatectomy: Prognostic Value of a Negative PSMA PET. J Nucl Med (2017) 58(12):1972-6. doi: 10.2967/jnumed.117.196683

90. Emmett L, Tang R, Nandurkar R, Hruby G, Roach P, Watts JA, et al. 3-Year Freedom From Progression After (68)Ga-PSMA PET/CT-Triaged Management in Men With Biochemical Recurrence After Radical Prostatectomy: Results of a Prospective Multicenter Trial. J Nucl Med (2020) 61(6):866-72. doi: 10.2967/jnumed.119.235028

91. Calais J, Armstrong W, Kishan A, Booker K, Hope T, Fendler W, et al. Update From PSMA-SRT Trial NCT03582774: A Randomized Phase 3 Imaging Trial of Prostate-Specific Membrane Antigen Positron Emission Tomography for Salvage Radiation Therapy for Prostate Cancer Recurrence Powered for Clinical Outcome. Eur Urol Focus (2021) 7:238-40. doi: 10.1016/ jeuf202012009

92. Cucchiara V, Cooperberg MR, Dall'Era M, Lin DW, Montorsi F, Schalken JA, et al. Genomic Markers in Prostate Cancer Decision Making. Eur Urol (2018) 73(4):572-82. doi: 10.1016/j.eururo.2017.10.036

93. Cooperberg MR, Simko JP, Cowan JE, Reid JE, Djalilvand A, Bhatnagar S, et al. Validation of a Cell-Cycle Progression Gene Panel to Improve Risk
Stratification in a Contemporary Prostatectomy Cohort. J Clin Oncol (2013) 31(11):1428-34. doi: 10.1200/JCO.2012.46.4396

94. Shore ND, Kella N, Moran B, Boczko J, Bianco FJ, Crawford ED, et al. Impact of the Cell Cycle Progression Test on Physician and Patient Treatment Selection for Localized Prostate Cancer. J Urol (2016) 195(3):612-8. doi: 10.1016/j.juro.2015.09.072

95. Spratt D, Yousefi K, Deheshi S, Ross A, Den R, Schaeffer E, et al. Individual Patient-Level Meta-Analysis of the Performance of the Decipher Genomic Classifier in High-Risk Men After Prostatectomy to Predict Development of Metastatic Disease. J Clin Oncol (2017) 35(18):1991-8. doi: 10.1200/ JCO2016702811

96. Cooperberg MR, Davicioni E, Crisan A, Jenkins RB, Ghadessi M, Karnes RJ. Combined Value of Validated Clinical and Genomic Risk Stratification Tools for Predicting Prostate Cancer Mortality in a High-Risk Prostatectomy Cohort. Eur Urol (2015) 67(2):326-33. doi: 10.1016/j.eururo.2014.05.039

97. Cantiello F, Crocerossa F, Russo GI, Gangemi V, Ferro M, Vartolomei MD, et al. Comparison Between (64)Cu-PSMA-617 PET/CT and (18)F-Choline PET/CT Imaging in Early Diagnosis of Prostate Cancer Biochemical Recurrence. Clin Genitourin Cancer (2018) 16(5):385-91. doi: 10.1016/ j.clgc.2018.05.014

98. Rauscher I, Kronke M, Konig M, Gafita A, Maurer T, Horn T, et al. MatchedPair Comparison of (68)Ga-PSMA-11 PET/CT and (18)F-PSMA-1007 PET/ CT: Frequency of Pitfalls and Detection Efficacy in Biochemical Recurrence After Radical Prostatectomy. J Nucl Med (2020) 61(1):51-7. doi: 10.2967/ jnumed.119.229187

99. Moazemi S, Erle A, Lutje S, Gaertner FC, Essler M, Bundschuh RA. Estimating the Potential of Radiomics Features and Radiomics Signature From Pretherapeutic PSMA-PET-CT Scans and Clinical Data for Prediction of Overall Survival When Treated With (177)Lu-PSMA. Diagnostics (Basel) (2021) 11(2):186. doi: 10.3390/diagnostics11020186

100. Zaidi H, ElNaqa I. Quantitative Molecular Positron Emission Tomography Imaging Using Advanced Deep Learning Techniques. Annu Rev BioMed Eng (2021) 23:249-76. doi: 10.1146/annurev-Bioeng-082420-020343

Conflict of Interest: The authors declare that the research was conducted in the absence of any commercial or financial relationships that could be construed as a potential conflict of interest.

Publisher's Note: All claims expressed in this article are solely those of the authors and do not necessarily represent those of their affiliated organizations, or those of the publisher, the editors and the reviewers. Any product that may be evaluated in this article, or claim that may be made by its manufacturer, is not guaranteed or endorsed by the publisher.

Copyright (C) 2021 le Guevelou, Achard, Mainta, Zaidi, Garibotto, Latorzeff, Sargos, Ménard and Zilli. This is an open-access article distributed under the terms of the Creative Commons Attribution License (CC BY). The use, distribution or reproduction in other forums is permitted, provided the original author(s) and the copyright owner(s) are credited and that the original publication in this journal is cited, in accordance with accepted academic practice. No use, distribution or reproduction is permitted which does not comply with these terms. 